\title{
Changes in the biogenic amine content of the prefrontal cortex, amygdala, dorsal hippocampus, and nucleus accumbens of rats submitted to single and repeated sessions of the elevated plus-maze test
}

M.C. Carvalho, L. Albrechet-Souza,

S. Masson and M.L. Brandão

\author{
Laboratório de Psicobiologia, Faculdade de Filosofia, \\ Ciências e Letras de Ribeirão Preto, Universidade de São Paulo, \\ Ribeirão Preto, SP, Brasil
}

\section{Correspondence \\ M.L. Brandão \\ Laboratório de Psicobiologia \\ FFCLRP, USP \\ Av. Bandeirantes, 3900 \\ 14049-901 Ribeirão Preto, SP \\ Brasil \\ Fax: +55-16-633-0619 \\ E-mail: mbrandao@usp.br \\ Research supported by FAPESP (No. 02/03705-0) and CNPq (No. 471783/2003-0). M.L. Brandão was the recipient of a fellowship from CNPq. M.C. Carvalho and L. Albrechet-Souza are recipients of master scholarships from CAPES}

Received April 6, 2005 Accepted August 26, 2005

\begin{abstract}
It has been demonstrated that exposure to a variety of stressful experiences enhances fearful reactions when behavior is tested in current animal models of anxiety. Until now, no study has examined the neurochemical changes during the test and retest sessions of rats submitted to the elevated plus maze (EPM). The present study uses a new approach (HPLC) by looking at the changes in dopamine and serotonin levels in the prefrontal cortex, amygdala, dorsal hippocampus, and nucleus accumbens in animals upon single or double exposure to the EPM (one-trial tolerance). The study involved two experiments: i) saline or midazolam $(0.5 \mathrm{mg} / \mathrm{kg})$ before the first trial, and ii) saline or midazolam before the second trial. For the biochemical analysis a control group injected with saline and not tested in the EPM was included. Stressful stimuli in the EPM were able to elicit one-trial tolerance to midazolam on re-exposure $(61.01 \%)$. Significant decreases in serotonin contents occurred in the prefrontal cortex (38.74\%), amygdala (78.96\%), dorsal hippocampus (70.33\%), and nucleus accumbens $(73.58 \%)$ of the animals tested in the EPM $(\mathrm{P}<0.05$ in all cases in relation to controls not exposed to the EPM). A significant decrease in dopamine content was also observed in the amygdala $(54.74 \%, \mathrm{P}<0.05)$. These changes were maintained across trials. There was no change in the turnover rates of these monoamines. We suggest that exposure to the EPM causes reduced monoaminergic neurotransmission activity in limbic structures, which appears to underlie the "one-trial tolerance" phenomenon.
\end{abstract}

Key words - One-trial tolerance

- Dopamine

- Serotonin

- Prefrontal cortex

- Amygdala

- Hippocampus 


\section{Introduction}

Numerous studies have demonstrated that a single exposure to a variety of stressful experiences enhances fearful reactions when behavior is subsequently tested in paradigms designed and currently used to evaluate anxiogenic and anxiolytic manipulations $(1,2)$. The traditional elevated plus-maze (EPM) test involves combinations of conditioned, innate, proximal, and distal aversive mechanisms such that aversive cues detected at a distance could function as a negative incentive that activates a fear system which guides the organism away from danger present in the open arms of the maze (3). It is believed that the use of the EPM as an animal model of anxiety is based on the conflict that results from the natural tendency of the animals when they are faced with dangerous situations (4). Accordingly, the nature of the threat, i.e., whether learned or innate, and the nature of the appropriate response (emission or suppression of an action) have a bearing on drug responses (5). In this context, while benzodiazepines (BZDs) injected in rats upon initial exposure to the EPM increase the percent of entries and the time spent in the open arms of the maze, a single previous undrugged experience in the EPM renders these compounds ineffective (6). This phenomenon, known as 'one-trial tolerance', appears to depend on the aversive learning triggered by the safety/danger conflict of the EPM in the first trial of the test (6,7). Furthermore, it has been reported that the impairment of the acquisition of aversive information about the EPM in naive animals treated with scopolamine before the first session, maintains the anxiolytic effect of BZDs on trial 2 (8). Recent behavioral studies have proposed that the submission to trial 1/trial 2 in the EPM results in a qualitative shift in emotional state (6-9).

The dopamine (DA) and serotonin (5HT) biogenic amine systems have been extensively studied in the neurobiology of fear and anxiety (1-5). A large number of studies using animal models of anxiety have been published regarding the tissue concentrations of these substances and metabolites in the structures involved in the mediation of affective responses. Indeed, a single exposure to diverse stressful situations causes multiple neurochemical changes in diverse neurotransmitter systems (2,10-12). However, the neural organization and neurochemical changes that occur during the test and retest sessions of the EPM of freely behaving rats are open to experimental analysis.

In the present study, we focused on the neurochemical changes in the brain of animals submitted to one or two sessions of the EPM test. We examined the neurochemical changes in the prefrontal cortex (PC), amygdala, nucleus accumbens (NAC), and dorsal hippocampus (DH) during one-trial learning development in rats and we determined to what extent midazolam injected before the first or second trial interferes with these neurochemical changes in rats exposed to the EPM.

These structures were chosen on the basis of the fact that they have important anatomical interactions and are involved in interdependent functional modalities that coordinate emotional and cognitive behavior (13). The amygdala is thought to mediate the processing and expression of emotional behavior (14). NAC provides an interface where stimuli with affective and emotional values access the motor effector sites and is also considered to be necessary for the expression of exploratory behavior $(13,15)$. PC is implicated in cognitive regulation of emotional reactivity (16). The hippocampus has been associated with the formation of memory traces and emotion-related behaviors $(4,17)$. As to this latter aspect, the DH has been considered to be part of the socalled behavioral inhibition system and it exerts a key role in the control of anxiety (4). All of these structures are part of the mesocorticolimbic system, in which biogenic 
amine levels are highly sensitive to exposure to a wide variety of acute stressors $(10,11,18)$.

For chemical analysis we used HPLC to determine the concentrations of the neurotransmitters DA and 5-HT and metabolites in animals injected with saline or midazolam upon single or double exposure to the EPM. The study consisted of two experiments: i) midazolam before the first trial $(\mathrm{M})$ and ii) midazolam before the second trial (SM).

\section{Material and Methods}

\section{Animals}

Male Wistar rats from the animal house of the Ribeirão Preto Campus, University of São Paulo, were used. The animals, weighing 230-250 g, were housed in individual Plexiglas-walled cages under a 12/12-h dark/ light cycle (lights on at 7:00 am) at $22 \pm 1^{\circ} \mathrm{C}$, and given free access to food and water throughout the experiment. The experiments reported in this article were performed in compliance with the recommendations of the Brazilian Society of Neuroscience and Behavior (SBNeC), which are based on the US National Institutes of Health Guide for Care and Use of Laboratory Animals (http://www.fesbe.org.br/sbnec).

\section{Apparatus}

Animals were submitted to the EPM for 5 min. The maze was made of wood with two open arms $(50 \times 10 \mathrm{~cm})$ and two enclosed arms of the same size with $50 \mathrm{~cm}$ high walls. The level of illumination was 50 lux on the floor level of the walled arms. The maze was configured so that arms of the same type were opposite to each other, and the whole maze was raised $50 \mathrm{~cm}$ from the floor. The walls of the closed arms were made of wood. The rats were placed individually in the center of the maze facing a closed arm and allowed $5 \mathrm{~min}$ of free exploration. The behavior of the animals was recorded with a videocamera positioned above the maze, allowing for the identification of all behaviors, with the signal relayed to a monitor in another room via a closed circuit TV camera. Each rat was tested only once. Videotapes were subsequently scored by an observer using ethological analysis software (Observer) developed by Noldus (Amsterdam, The Netherlands). Using separate location and behavior keys, this software allows the real-time scoring of videotapes of any behavior by direct keyboard entry to a personal computer.

\section{Procedure}

Midazolam $(0.5 \mathrm{mg} / \mathrm{kg}$; Roche Produtos Químicos e Farmacêuticos S.A., São Paulo, $\mathrm{SP}$, Brazil) was dissolved in $0.9 \%$ saline solution shortly before use. We assessed the exploratory behavior and neurochemical changes in rats injected with saline or midazolam $(0.5 \mathrm{mg} / \mathrm{kg})$ and exposed once or twice to the EPM. Therefore, the present study involved two experiments. To analyze the effects of one exposure to the EPM the animals were allocated at random to two groups ( $\mathrm{N}=11$ in each group): a) $\mathrm{S}$, injected with saline; b) M, injected with midazolam. In the second experiment, carried out to analyze the effects of repeated exposures, the animals were also allocated at random to two other groups ( $\mathrm{N}=11$ in each group): a) SS, injected with saline before both trials; $b$ ) SM, injected with saline before the first trial and with midazolam before the second trial. The animals were tested $15 \mathrm{~min}$ after the injections. Selection of midazolam dose and time for testing were based on previous studies from this laboratory $(9,19,20)$. In these studies an ethopharmacological analysis was conducted to characterize the one-trial tolerance to midazolam in terms of a thorough dose-response relationship. The interval between sessions was of $24 \mathrm{~h}$. This interval is commonly used in studies on one-trial tolerance to BZD (7-9). The substances were 
injected intraperitoneally $15 \mathrm{~min}$ before the trials. In the neurochemical study, an additional group of rats injected with saline and not exposed to the EPM was studied (control group, $\mathrm{C}, \mathrm{N}=8$ ). This control group was taken to the experimental room where they were injected with saline and remained in their cages for $20 \mathrm{~min}$ before sacrifice for the monoamine assays as described below. In the behavioral tests the number of animals per group was equal to 11 and in the neurochemical assays the number of samples per structure in each group was equal to 8 .

\section{Monoamine assays}

Immediately after exposures to the EPM the animals were lightly anesthetized with carbon dioxide for $2 \mathrm{~min}$ and sacrificed by decapitation. The brains were removed from the skull, placed on ice and sliced $(2 \mathrm{~mm})$, with the bregma considered to be the reference landmark. Next, four areas from each side of the brain were dissected out taking as reference the following plates indicated in the Paxinos and Watson atlas (21): PC (plate 6), NAC (plate 15), amygdala (plate 30), and hippocampus (plate 38). The HPLC system was equipped with a reverse-phase column (Hypurity Elite C18, $250 \mathrm{~mm} \times 4.6 \mathrm{~mm}$, $5 \mu \mathrm{m}$ and 100 - $\AA$ pore diameter particle size; Hypersil, Cheshire, UK), coupled with electrochemical detection. The samples were homogenized in $0.2 \mathrm{M}$ perchloric acid containing dihydroxy-benzylamine (DHBA), centrifuged at $15,000 \mathrm{rpm}$ for $20 \mathrm{~min}$ at $6^{\circ} \mathrm{C}$ and stored at $-70^{\circ} \mathrm{C}$ for 15 days, and $50 \mu \mathrm{L}$ was injected into the HPLC-EC system. The addition of DHBA to the tissue extracts from rats non-exposed and exposed to the EPM served as an internal standard to control for loss of tissue contents. The HPLC system consisted of a Shimadzu LC-10 AD chromatograph, with a CBM-10A communication bus module, an on-line DGU-14A degassing unit, and an L-ECD-6A electrochemical detector with a glassy-carbon electrode, and an LC-10 AD pump. The potential was set at $850 \mathrm{mV}$ (versus an $\mathrm{Ag} / \mathrm{AgCl}$ reference electrode). The mobile phase containing $150 \mathrm{mM}$ chloroacetic acid, $120 \mathrm{mM} \mathrm{NaOH}$, $0.67 \mathrm{mM}$ EDTA, $0.86 \mathrm{mM}$ sodium octylsulfate, $3.5 \%$ acetonitrile, and $2.6 \%$ tetrahydrofuran, adjusted to $\mathrm{pH} 3.0$, was filtered and pumped through the system at a flow rate of $1.2 \mathrm{~mL} / \mathrm{min}$. All substances were quantified by comparing the peak areas to standard curves. The 5-hydroxyindoleacetic acid (5-HIAA)/5-HT and 3.4-dihydroxyphenylacetic acid (DOPAC)/DA ratios were used as indices of serotonergic and dopaminergic activity, respectively $(22,23)$.

\section{Statistical analysis}

Data are reported as means \pm SEM. The behavioral data of the first experiment were analyzed by two-way ANOVA. For the biochemical analyses, the data for each substance (DA, 5-HT, DOPAC, and 5-HIAA) measured in the PC, amygdala, NAC, and $\mathrm{DH}$ of all groups of animals were analyzed by one-way ANOVA. Post hoc differences between group means were determined by the Duncan test. The level of significance was $\mathrm{P}<0.05$ in all analyses.

\section{Results}

\section{Behavioral measures}

The effects of saline and midazolam, 0.5 $\mathrm{mg} / \mathrm{kg}$, injected before trial 1 (T1, S and $\mathrm{M}$, respectively) and trial 2 (T2, SS and SM) on the behavior of rats submitted to the EPM are illustrated in Figure 1. Two-way ANOVA revealed a significant effect of sessions on number of open arm entries $(\mathrm{F}(1,40)=17.1 ; \mathrm{P}$ $<0.05)$. Post hoc analysis revealed an increase in the number of entries into the open arms in group $\mathrm{M}$ compared to $\mathrm{S}$ and a decrease in the open arm entries in the retest compared to the test session. There was a trend towards significance for treatments $(\mathrm{F}(1,40)=3.29 ; \mathrm{P}=$ 
$0.07)$ but no treatment-session interaction regarding the number of open arm entries $(\mathrm{F}(1,40)$ $=1.18 ; \mathrm{P}>0.05)$. Two-way ANOVA showed no significant differences between treatments $(\mathrm{F}(1,40)=0.30 ; \mathrm{P}>0.05)$ and sessions $(\mathrm{F}(1,40)$ $=3.08 ; \mathrm{P}>0.05)$ or treatment-session interaction regarding closed arm entries $(\mathrm{F}(1,40)=$ $0.10 ; \mathrm{P}>0.05)$.

Two-way ANOVA showed significant differences between treatments $(\mathrm{F}(1,40)=$ $4.33 ; \mathrm{P}<0.05)$ and sessions $(\mathrm{F}(1,40)=25.26$; $\mathrm{P}<0.05)$ but no significant treatment-session interaction $(\mathrm{F}(1,40)=2.32 ; \mathrm{P}>0.05)$ regarding the percentage of time spent in the open arms. Post hoc analysis revealed an increase in group $\mathrm{M}$ in relation to $\mathrm{S}$ and a decrease in the open arm entries in the retest in relation to the test session. As to the percentage of open arms entries, two-way ANOVA showed significant differences between sessions $(\mathrm{F}(1,40)=24.23 ; \mathrm{P}<0.05)$ but did not detect any significant differences between treatments $(\mathrm{F}(1,40)=3.46 ; \mathrm{P}>$ $0.05)$. There was no significant treatmentsession interaction $(\mathrm{F}(1,40)=1.14 ; \mathrm{P}>0.05)$. Post hoc analysis revealed that both groups showed a decrease in the percent of open arm entries in the retest.

\section{Biochemistry}

An internal standard was used concomitant with the experimental samples from storage to analysis by HPLC to assure greater reliability to our data. Indeed, the tissue content of biogenic amines in control animals not exposed to the EPM in this study is within the range reported in other studies that used this technique (16,22-24). Table 1 shows that animals treated with saline or midazolam and exposed to one or two sessions in the EPM did not present differences in 5-HT or dopamine turnover in relation to the controls (C).

\section{Frontal cortex}

Figure 2A and B shows the contents of 5-

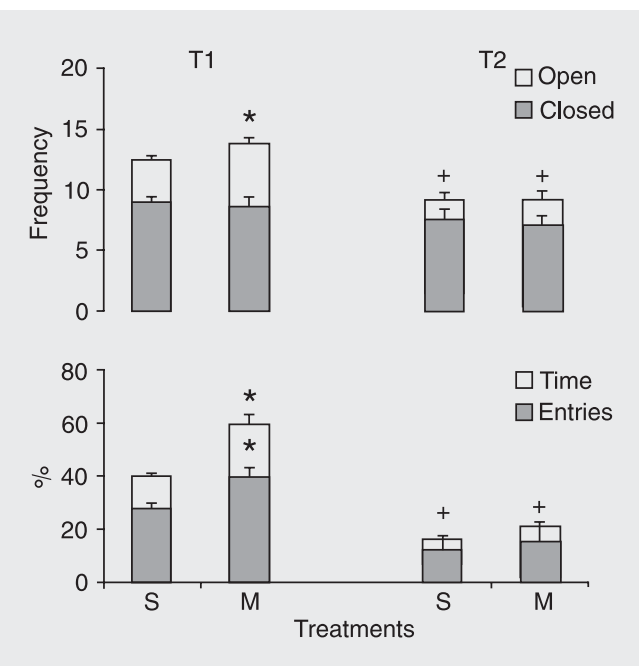

Figure 1. Effect of midazolam injected before the first trial on the exploratory behavior of rats submitted to trial 1 (T1) and trial 2 (T2) of the elevated plus-maze test. Top, Number of entries into both types of arms. Bottom, Percent of entries and time spent in the open arms in relation to the total numbers. Each animal was treated with saline (control) or $0.5 \mathrm{mg} / \mathrm{kg}$ midazolam before $\mathrm{T} 1$. Data are reported as means \pm SEM for $\mathrm{N}=11$ animals in each group. $S=$ saline; $M=0.5 \mathrm{mg} / \mathrm{kg}$ midazolam. ${ }^{*} \mathrm{P}<0.05$ compared to control (saline in $\mathrm{T} 1$ ); $+\mathrm{P}<$ 0.05 compared to the corresponding group in T1 (Duncan test).

Table 1. Turnover of serotonin dopamine in the prefrontal cortex, amygdala, dorsal hippocampus, and nucleus accumbens of rats submitted to trial 1 (T1) and trial 2 (T2) of the elevated plus-maze test.

\begin{tabular}{|c|c|c|}
\hline & $5-\mathrm{HT}$ & DA \\
\hline \multicolumn{3}{|c|}{ Prefrontal cortex } \\
\hline Control & $0.32 \pm 0.03$ & $0.16 \pm 0.05$ \\
\hline$S$ & $0.27 \pm 0.02$ & $0.03 \pm 0.03$ \\
\hline$M$ & $0.30 \pm 0.05$ & $0.12 \pm 0.07$ \\
\hline ss & $0.29 \pm 0.03$ & $0.04 \pm 0.03$ \\
\hline SM & $0.26 \pm 0.03$ & $0.03 \pm 0.03$ \\
\hline ANOVA & $F(4,35)=0.47, P>0.05$ & $F(4,35)=1.87, P>0.05$ \\
\hline \multicolumn{3}{|l|}{ Amygdala } \\
\hline Control & $0.36 \pm 0.02$ & $0.09 \pm 0.01$ \\
\hline $\mathrm{S}$ & $0.41 \pm 0.06$ & $0.07 \pm 0.01$ \\
\hline$M$ & $0.38 \pm 0.03$ & $0.06 \pm 0.01$ \\
\hline SS & $0.39 \pm 0.03$ & $0.13 \pm 0.04$ \\
\hline SM & $0.36 \pm 0.04$ & $0.09 \pm 0.02$ \\
\hline ANOVA & $F(4,35)=1.87, P>0.05$ & $F(4,35)=1.82, P>0.05$ \\
\hline \multicolumn{3}{|c|}{ Dorsal hippocampus } \\
\hline Control & $0.53 \pm 0.07$ & $0.01 \pm 0.01$ \\
\hline $\mathrm{s}$ & $0.56 \pm 0.07$ & $0.01 \pm 0.01$ \\
\hline M & $0.51 \pm 0.06$ & $0.53 \pm 0.02$ \\
\hline SS & $0.55 \pm 0.04$ & $0.03 \pm 0.02$ \\
\hline SM & $0.49 \pm 0.02$ & $0.04 \pm 0.02$ \\
\hline ANOVA & $F(4,35)=2.32, P>0.05$ & $F(4,35)=0.85, P>0.05$ \\
\hline \multicolumn{3}{|c|}{ Nucleus accumbens } \\
\hline Control & $0.33 \pm 0.02$ & $0.09 \pm 0.01$ \\
\hline $\mathrm{S}$ & $0.41 \pm 0.03$ & $0.11 \pm 0.01$ \\
\hline M & $0.45 \pm 0.07$ & $0.11 \pm 0.01$ \\
\hline ss & $0.37 \pm 0.04$ & $0.10 \pm 0.01$ \\
\hline SM & $0.36 \pm 0.03$ & $0.11 \pm 0.01$ \\
\hline ANOVA & $F(4,35)=1.34, P>0.05$ & $F(4,35)=0.85, P>0.05$ \\
\hline \multicolumn{3}{|c|}{$\begin{array}{l}\text { Data are reported as means } \pm \mathrm{SEM} \text { for } \mathrm{N}=8 \text { animals in each group. The interval between } \mathrm{T} 1 \\
\text { and } \mathrm{T} 2 \text { was of } 24 \mathrm{~h} \text {. Control = group not tested in the elevated plus-maze test; } \mathrm{S}=\text { saline in } \mathrm{T} 1 \\
\mathrm{M}=\text { midazolam }(0.5 \mathrm{mg} / \mathrm{kg}) \text { in } \mathrm{T} 1 ; \mathrm{SS}=\text { saline in } \mathrm{T} 1 \text { and } \mathrm{T} 2 ; \mathrm{SM}=\text { saline in } \mathrm{T} 1 \text { and midazolam } \\
\text { in } \mathrm{T} 2.5-\mathrm{HT}=\text { serotonin; } \mathrm{DA}=\text { dopamine. No significant differences were detected between } \\
\text { groups by one-way ANOVA applied to the data recorded for each structure. }\end{array}$} \\
\hline
\end{tabular}


Figure 2. Levels of neurotransmitters in the prefrontal cortex of rats after they were submitted to one (trial 1, T1) or two (trial 2, T2) sessions on the elevated plus-maze test. $A$, Serotonin (5$\mathrm{HT}$ ) and 5-hydroxyindoleacetic acid (5-HIAA). B, Dopamine (DA) and dihydroxyphenylacetic acid (DOPAC). The neurochemical values ( $\mathrm{ng} / \mathrm{mg}$ wet weight of tissue; mean \pm SEM) were measured in the brains of rats treated with saline or $0.5 \mathrm{mg} / \mathrm{kg}$ midazolam. $\mathrm{N}=8$ for each group. ${ }^{*} P<0.05$ compared to control (Duncan test).

Figure 3. Levels of neurotransmitters in the amygdala of rats after they were submitted to one (trial 1, T1) or two (trial 2, T2) sessions on the elevated plusmaze test. $A$, Serotonin (5-HT) and 5-hydroxyindoleacetic acid (5-HIAA). B, Dopamine (DA) and dihydroxyphenylacetic acid (DOPAC). The neurochemical values ( $\mathrm{ng} / \mathrm{mg}$ wet weight of tissue; mean \pm SEM) were measured in the brains of rats treated with saline or $0.5 \mathrm{mg} / \mathrm{kg}$ midazolam. $\mathrm{N}=8$ for each group. ${ }^{*} \mathrm{P}<$ 0.05 compared to control (Duncan test).

Figure 4. Levels of neurotransmitters in the dorsal hippocampus of rats after they were submitted to one (trial 1, T1) or two (trial 2, T2) sessions on elevated plus-maze test. $A$, Serotonin (5$\mathrm{HT}$ ) and 5-hydroxyindoleacetic acid (5-HIAA). B, Dopamine (DA) and dihydroxyphenylacetic acid (DOPAC). The neurochemical values ( $\mathrm{ng} / \mathrm{mg}$ wet weight of tissue; mean \pm SEM) were measured in the brains of rats treated with saline or $0.5 \mathrm{mg} / \mathrm{kg}$ midazolam. $\mathrm{N}=8$ for each group. ${ }^{*} \mathrm{P}<0.05$ compared to control (Duncan test).

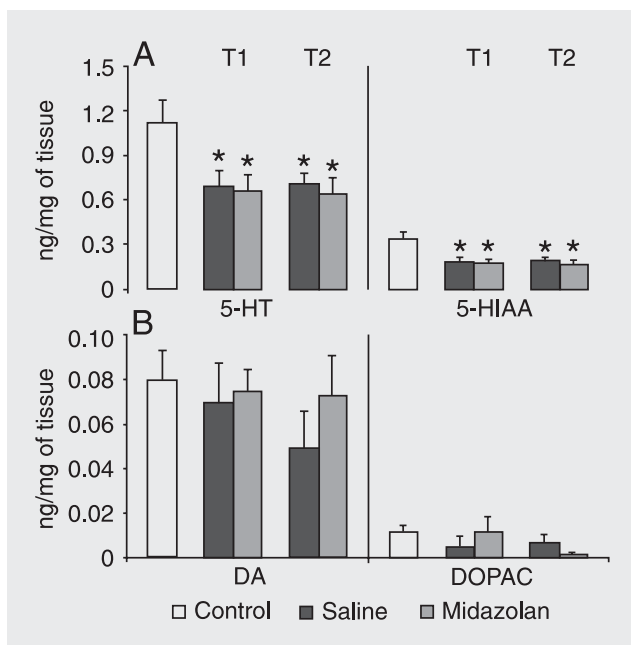

HT $v s$ 5-HIAA and DA $v s$ DOPAC, respectively, measured in the PC of rats injected with saline or midazolam and submitted to one (T1) or two (T2) EPM sessions. 5-HT and 5-HIAA concentrations changed significantly in the PC of rats injected with saline or midazolam $(\mathrm{F}(4,35)=3.01$ and 5.86, for 5-HT and 5-HIAA; $\mathrm{P}<0.05$ in both cases). Post hoc analysis indicated that significant decreases were observed in all experimental groups compared to the non-exposed control group. Tissue levels of DA and DOPAC did not change significantly in the PC of rats submitted to the EPM after injection of saline or midazolam $(\mathrm{F}(4,35)=$ 0.55 and 1.03 , for DA and DOPAC, respectively; $\mathrm{P}>0.05$ in both cases).

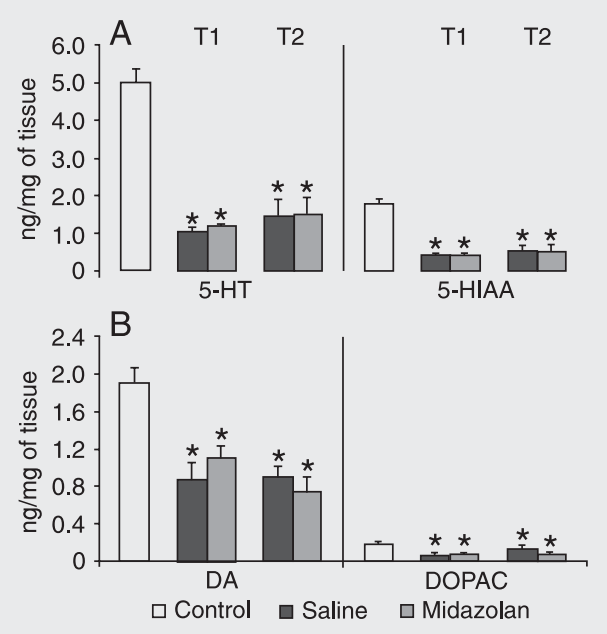

\section{Amygdala}

Figure $3 \mathrm{~A}$ and $\mathrm{B}$ shows the contents of 5-HT vs 5-HIAA and DA vs DOPAC, respectively, measured in the amygdala of rats injected with saline or midazolam and submitted to single or double EPM sessions. Concentrations of 5-HT and 5-HIAA changed significantly in the amygdala of rats treated with saline or midazolam $(\mathrm{F}(4,35)=22.98$ and 24.75 , for 5 -HT and 5-HIAA; $\mathrm{P}<0.05$ in both cases). Post hoc analysis indicated that significant decreases were observed in all experimental groups compared to the untested control group of animals. Tissue levels of DA and DOPAC were significantly reduced in the amygdala of rats submitted to the EPM after injection of saline or midazolam $(F(4,35)=8.97$ and 3.29 for DA and DOPAC, respectively; $\mathrm{P}<0.05$ in both cases). Post hoc analysis revealed that significant decreases were observed in all groups compared to the untested controls.

\section{Dorsal hippocampus}

Figure 4A and $B$ shows the contents of 5HT vs 5-HIAA and DA vs DOPAC, respectively, measured in the DH of rats injected 
with saline or midazolam and submitted once or twice to the EPM test. Concentrations of 5-HT and 5-HIAA changed significantly in the amygdala of rats treated with saline or midazolam $(\mathrm{F}(4,35)=16.38$ and 47.60 for 5 HT and 5-HIAA; $\mathrm{P}<0.05$ in both cases). Post hoc analysis indicated that significant decreases were observed in all experimental groups compared to the non-exposed control group. Tissue levels of DA and DOPAC did not change significantly in the $\mathrm{DH}$ of rats submitted to the EPM $(F(4,35)=0.52$ and 0.95 for DA and DOPAC, respectively; P > 0.05 in both cases).

\section{Nucleus accumbens}

Figure $5 \mathrm{~A}$ and $\mathrm{B}$ shows the contents of 5HT vs 5-HIAA and DA vs DOPAC, respectively, measured in the NAC of rats injected with saline or midazolam and submitted to T1 and T2 EPM sessions. 5-HT and 5-HIAA contents in NAC changed significantly in rats exposed to both sessions of the EPM $(\mathrm{F}(4,35)=10.12$ and 12.61 for 5-HT and 5HIAA; P $<0.05$ in both cases). Post hoc analysis indicated that significant decreases were observed in all experimental groups compared to the non-exposed control group. Tissue levels of DA and DOPAC did not change significantly in the NAC of rats submitted to the EPM after injection of saline or midazolam $(F(4,35)=1.37$ and 1.25 , for $\mathrm{DA}$ and DOPAC, respectively; $\mathrm{P}>0.05$ in both cases).

\section{Discussion}

One-trial tolerance to the effects of midazolam was the most prominent behavioral effect of reexposure of the animals to the EPM. Although the anxiolytic-like effect of midazolam was apparent during the 1st trial, it did not change the exploratory activity in the 2 nd trial compared to control. It has been suggested that the "anxiolytic-like" effect of BZD in the EPM test depends on the conflict that results from the need to approach the danger of the open arms and the need to leave the safety of the enclosed arms (5-8). In this context, Rodgers and Shepherd (24) suggested that the loss of diazepam efficacy in trial 2 might reflect the relative absence of an approach/avoid conflict. In support of this claim, no significant change in closed arm entries was observed in the animals submitted to repeated exposures to the EPM, ruling out the possibility of habituation to the environment, which has also been proposed to underlie the one-trial tolerance phenomenon (25). However, prior closed arm experience also seems to be crucial for the subsequent loss of BZD anxiolysis (24). Thus, the EPM test is not as simple as it appears and is very sensitive to small exogenous changes so that it can measure a variety of defensive responses to stress. For instance, it has been shown that isolation for a 2-h period is sufficient to reduce exploratory behavior in the EPM (1). Similarly, a restraint period of $15 \mathrm{~min}$ before the EPM test also reduces the performance of rats in the test (2). Therefore, a previous history of stress may sensitize a defensive mechanism in reaction to subsequent novel aversive stimuli. Indeed, sensitization to subsequent stressors in animals previously exposed to stress has been documented on the basis of

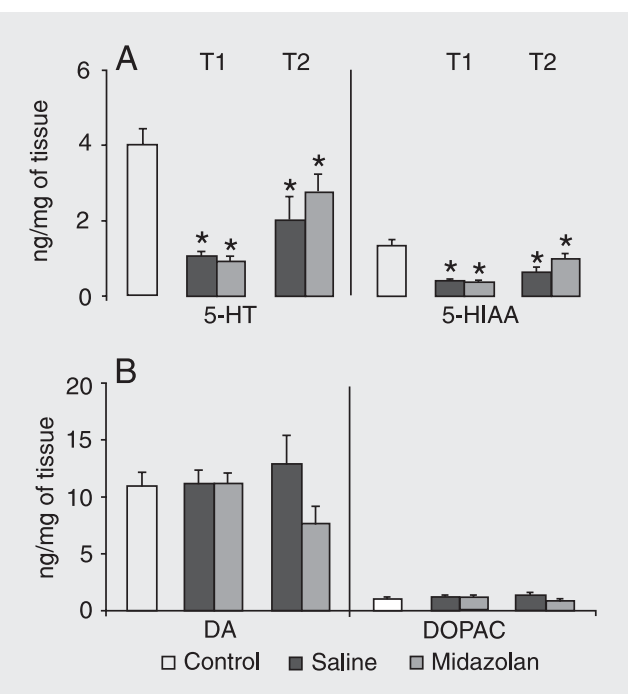

Figure 5. Levels of neurotransmitters in the nucleus accumbens of rats after they were submitted to one (trial 1, T1) or two (trial 2, T2) sessions on elevated plus-maze test. $A$, Serotonin (5HT) and 5-hydroxyindoleacetic acid (5-HIAA). B, Dopamine (DA) and dihydroxyphenylacetic acid (DOPAC). The neurochemical values $(\mathrm{ng} / \mathrm{mg}$ wet weight of tissue; mean \pm SEM) were measured in the brains of rats treated with saline or $0.5 \mathrm{mg} / \mathrm{kg}$ midazolam. $\mathrm{N}=8$ for each group. ${ }^{*} P<0.05$ compared to control (Duncan test). 
hormonal, neurochemical and immunological variables (26).

The main findings of the present neurochemistry studies were: i) decrease in the content of 5-HT in all limbic structures studied soon after both sessions of the EPM; ii) midazolam did not reverse these changes in the test and retest sessions; iii) the amygdala was the only structure in which there was a reduction in the tissue concentrations of DA and DOPAC across sessions; iv) these changes in the neurotransmission of 5-HT and DA in these structures cannot be attributed to enhanced metabolism since the turnover rates of these biogenic amines were not different from those of control animals not tested in the EPM.

The present results suggest that the exposure to the height and open spaces of the open arms to the EPM causes a significant decrease in 5-HT concentration in the PC, amygdala, DH, and NAC. It has been suggested that serotonin plays a role in the regulation of emotional responses in these limbic structures (3). In the present study, 5HT levels in these structures were kept significantly low after the first exposure to the EPM. It has been shown that animals reduce their exploratory activity in the second half of the first session of the EPM $(7,8)$. Therefore, the reduction in 5-HT content obtained following the first session and its maintenance after the second trial could be related to the repeated stressful experience of the EPM. Serotonergic mechanisms of the mesolimbic system, particularly at the level of these structures, are crucial in the processing of aversive information $(3,16)$. It has been shown that changes in 5-HT release in the amygdala seem to depend on the stressor to which the animals are exposed. For instance, inescapable shocks, but not escapable ones, cause increases in 5-HT release in the basolateral amygdala (27). The amygdala appears to play a particular role in the defensive behavior of the animals submitted to the EPM. Indeed, it was the only structure in which the dopaminergic function decreased after both trials. Involvement of mesoamygdaloid DA fear arousal is a possible explanation for the present results (28). In agreement with this view, several studies have shown that DA mechanisms of the ventral tegmental area are involved in fear arousal in response to unconditioned aversive stimuli $(29,30)$. Indeed, the most prominent aversive stimuli of the EPM, height and open spaces, are innate aversive stimuli for rodents. More interestingly, reduction in the functioning of this pathway has been reported to be responsible for deficits in emotional behaviors (30).

The NAC provides an interface where stimuli with affective and emotional value access the motor effector sites (15). Since this test evaluates the emotional reactivity of the animals through the combination of motor activity and fear of open spaces and height we also included in the analysis the NAC. The NAC has also been claimed to be an important output center for emotional responses and changes in its monoamine contents could also be implicated in several brain disorders, including anxiety (31). As components of the limbic system, the amygdala, hippocampus, NAC, and PC are involved in interdependent functional modalities that coordinate emotional and cognitive behavior (16). The present results showed that the exposure to height and open spaces of the open arms of the EPM causes a decrease in 5-HT concentrations in the NAC. Therefore, exposure to the stressful stimuli of the EPM test results in recruitment of the serotonergic system innervating the NAC.

The decrease in 5-HT content in the limbic structures studied here seems to be a long-lasting effect since it persisted $24 \mathrm{~h}$ later after re-exposure to the EPM test. This is supported by a recent report showing that the serotonergic activity in the dorsal raphe nucleus was significantly lower in rats submitted to the EPM test and sacrificed either immediately or 10-12 days later the test 
$(22,23)$. This prolonged reduction in the concentration of this biogenic amine after the animals are exposed to the EPM test reinforces the suggestion of a long-lasting effect of the first exposure to the EPM, which may have an impact on the performance of the animals in subsequent tests.

The present results suggest that past stressful experiences resulted in important changes in 5-HT transmission in limbic structures. Given the key role of 5-HT inhibitory transmission in controlling chronic stress, the altered regulation of the emotional states after past stressful experiences by this neurotransmitter may represent a mechanism underlying certain types of anxiety disorders. Indeed, psychological stress associated with dysregulation of central monoamine systems in the PC, amygdala, DH, and NAC has been proposed to play a role in the development of the pathophysiology of anxiety (16,32-34). The concomitant changes in DA in the amygdala and in 5-HT content in limbic structures suggest a role for the amygdala in the afferent channels to the neural system activated by aversive events such as those inherent to the EPM test $(27,28,33)$. This may be clinically relevant because cortical and limbic DA and 5-HT dysfunction is proposed to play a role in anxiety (16,27-34). Reduced 5-HT and DA inputs from cortical structures and amygdala to the NAC may be an important neurobiological substrate for the mediation of symptom exacerbation in some types of anxiety disorders, such as the post-traumatic stress disorder $(35,36)$. Thus, the present findings integrate these factors and may herefore contribute to our understanding of some types of anxiety.

Finally, it is important to mention that it would be helpful if we could rely on the microdialysis technique to offer direct support for the present findings with post-mortem analysis of the tissue. However, the microdialysis technique cannot detect changes in a reliable way during a 5-min test (EPM). Besides, microdialysis is usually done in one structure at a time whereas in this study we had an overview of the concomitant changes in several structures of the limbic system. Thus, for the purposes of this research, the analysis of the tissue content of biogenic amines continues to provide very useful information.

\section{References}

1. Maisonnette SS, Morato S \& Brandão ML (1993). Role of resocialization and of 5-HT1A receptor activation on the anxiogenic effects induced by isolation in the elevated plus maze test. Physiology and Behavior, 54: 753-758.

2. Maritjena ID, Calvo N, Volosin M et al. (1997). Prior exposure to a brief restraint session facilitates the occurrence of fear in response to a conflict situation: behavioral and neurochemical correlates. Brain Research, 752: 136-142.

3. Graeff FG \& Deakin JFW (1991). 5-HT and mechanisms of defence. Journal of Psychopharmacology, 5: 305-315.

4. Gray JA \& McNaughton N (2000). Fundamentals of the septohippocampal system. In: Gray JA \& McNaughton N (Editors), Neuropsychology of Anxiety. 2nd edn. Oxford University Press, Oxford, UK.

5. Handley SL \& McBlane JW (1993). 5-HT drugs in animal models of anxiety. Psychopharmacology, 112: 13-20.

6. File SE \& Zangrossi H (1993). "One trial tolerance" to the anxiolytic actions of benzodiazepine in the elevated plus-maze, or the development of a phobic state? Psychopharmacology, 110: 240-244.
7. Bertoglio LJ \& Carobrez AP (2000). Previous maze experience required to increase open arms avoidance in rats submitted to the elevated plus-maze model of anxiety. Behavioural Brain Research, 108: 197-203.

8. Bertoglio LJ \& Carobrez AP (2004). Scopolamine given pre-trial 1 prevents the one-trial tolerance phenomenon in the elevated plusmaze trial 2. Behavioural Pharmacology, 15: 45-54.

9. Cruz-Morales SE, Santos NR \& Brandão ML (2002). One-trial tolerance to midazolam is due to enhancement of fear and reduction of anxiolytic-sensitive behaviors in the elevated plus-maze retest in the rat. Pharmacology, Biochemistry, and Behavior, 72: 973-978.

10. Cuadra G, Zurita A, Lacerra C et al. (1999). Chronic stress sensitizes frontal cortex dopamine release in response to a subsequent novel stressor: reversal by naloxone. Brain Research Bulletin, 48: 303-308.

11. Cuadra G, Zurita A, Macedo CE et al. (2000). Electrical stimulation of the midbrain tectum enhances dopamine release in the frontal cortex. Brain Research Bulletin, 52: 413-418.

12. Zurita A, Maritjena I, Cuadra G et al. (2000). Early exposure to 
chronic variable stress facilitates the occurrence of anhedonia and enhanced emotional reactions to novel stressors: reversal by naltrexone pretreatment. Behavioural Brain Research, 117: 163-171.

13. Jackson ME \& Moghaddam B (2001). Amygdala regulation of nucleus accumbens dopamine output is governed by the prefrontal cortex. Journal of Neuroscience, 21: 676-681.

14. Gallagher M \& Holland P (1994). The amygdala complex: Multiple roles in associative learning and attention. Proceedings of the $\mathrm{Na}$ tional Academy of Sciences, USA, 1: 11771-11776.

15. Mogenson G, Jones D \& Yim C (1980). From motivation to action: functional interface between the limbic system and the motor system. Progress in Neurobiology, 14: 69-97.

16. Goldstein LE, Rasmusson AM, Bunney BS et al. (1996). Role of the amygdala in the coordination of behavioral, neuroendocrine, and prefrontal cortical monoamine responses to psychological stress in the rat. Journal of Neuroscience, 16: 4787-4798.

17. Mongeau R, Blier P \& de Montigny C (1997). The serotoninergic and noradrenergic systems of the hippocampus: their interactions and the effects of antidepressant treatments. Brain Research Reviews, 23: $145-195$

18. Feenstra MGP, Botterblom MHA \& Van Uum JFM (1995). Noveltyinduced increase in dopamine release in the rat prefrontal cortex in vivo: Inhibition by diazepam. Neuroscience Letters, 189: 81-84.

19. Anseloni VCZ \& Brandão ML (1997). Ethopharmacological analysis of behaviour of rats using variations of the elevated plus-maze. Behavioural Pharmacology, 8: 533-540.

20. Albrechet-Souza L, Oliveira AR, DeLuca MCZ et al. (2005). A comparative study with two types of elevated plus-maze (transparent vs opaque walls) on the effects of midazolam, one-trial tolerance and fear-induced analgesia. Progress in Neuro-Psychopharmacology and Biological Psychiatry, 29: 571-579.

21. Paxinos G \& Watson C (1997). The Rat Brain in Stereotaxic Coordinates. Academic Press, New York.

22. Dominguez R, Cruz-Morales SE, Carvalho MC et al. (2003). Sex differences in serotonergic activity in dorsal and median raphe nucleus. Physiology and Behavior, 80: 203-210.

23. Dominguez R, Cruz-Moralez SE, Carvalho MC et al. (2003). Effect of steroid injection to newborn rats on serotonin activity in frontal cortex and raphe. NeuroReport, 14: 597-599.

24. Rodgers RJ \& Shepherd JK (1993). Influence of prior maze experience on behaviour and response to diazepam in the elevated plusmaze and light/dark tests of anxiety in mice. Psychopharmacology, 113: 237-242.

25. Dawson GR, Crawford SP, Stanhope KJ et al. (1994). One-trial tolerance to the effects of chlordiazepoxide on the elevated plusmaze may be due to locomotor habituation, not repeated drug exposure. Psychopharmacology, 113: 570-572.

26. Antelman SM, Cunnick JE, Lysle DT et al. (1990). Immobilization 12 days (but not one hour) earlier enhanced 2-deoxy-D-glucose induced immunosuppression; evidence for stressor-induced time dependent sensitization of the immune system. Progress in NeuroPsychopharmacology and Biological Psychiatry, 14: 579-590.

27. Amat J, Amat PM, Watkins LR et al. (1998). Escapable and inescapable stress differentially alter extracellular levels of 5-HT in the basolateral amygdala of the rat. Brain Research, 812: 113-120.

28. Inglis FM \& Moghaddam B (1999). Dopaminergic innervation of the amygdala is highly responsive to stress. Journal of Neurochemistry, 72: 1088-1094.

29. Gifkins A, Greba $Q$ \& Kokkinidis $L$ (2002). Ventral tegmental area dopamine neurons mediate the shock sensitization of acoustic startle: A potential site of action for benzodiazepine anxiolytics. Behavioral Neuroscience, 116: 785-794.

30. Greba Q, Gifkins A \& Kokkinidis L (2001). Inhibition of amygdaloid dopamine D2 receptors impairs emotional learning measured with fear-potentiated startle. Brain Research, 899: 219-226.

31. Sesack SR \& Pickel VM (1992). Prefrontal cortical efferents in the rat synapse on unlabeled neuronal targets of catecholamine terminal in the nucleus accumbens septi and on dopamine neurons in the ventral tegmental area. Journal of Comparative Neurology, 320: 145-160.

32. Goldstein LE, Rasmusson AM, Bunney BS et al. (1994). The NMDA glycine site antagonist (+)-HA-966 selectively regulates conditioned stress-induced metabolic activation of the mesoprefrontal cortical dopamine but not serotonin systems: a behavioral, neuroendocrine, and neurochemical study in the rat. Journal of Neuroscience, 14: 4937-4950.

33. Millan MJ (2003). The neurobiology and control of anxious states. Progress in Neurobiology, 70: 83-244.

34. Morrow BA, Elsworth JD, Rasmusson AM et al. (1999). The role of mesofrontal dopamine neurons in the acquisition and expression of conditioned fear in the rat. Neuroscience, 92: 553-564.

35. Charney DS, Deutch AY, Krystal JH et al. (1993). Psychobiologic mechanisms of posttraumatic stress disorder. Archives of General Psychiatry, 50: 294-305.

36. Post RM (1992). Transduction of psychosocial stress into the neurobiology of recurrent affective disorder. American Journal of Physiology, 149: 999-1010. 